\title{
GREENHOUSE PLASTIC FILMS CAPABLE OF MODIFYING THE SPECTRAL DISTRIBUTION OF SOLAR RADIATION
}

\author{
Evelia Schettini, Giuliano Vox
}

\section{Introduction}

The use of plastic films to cover orchards is expanding since ripening time can be forced or delayed in accordance with market demand and fruit quality parameters, such as colour and sugar content, can be improved. The function of the covering films is to increase the air temperature around the trees by allowing solar radiation to pass through the coverings while reducing the radiative and convective energy losses [Papadakis 2000]. Moreover plastic films protect fruit trees from adverse weather conditions, such as rain, hail, spring frost, wind and snow, and may reduce fungal diseases. One of the principal problems with tree cultivation in greenhouses is the control of plant height, which can be achieved with the use of growth regulators [Wilson 2001] but is preferably accomplished with agronomic techniques including dwarfing rootstocks, a regulated irrigation deficit, and a modified radiation environment [Clifford 2004; Dichio 2004; Rajapakse 1999; Shahak 2004]. Particularly, spectral wavelength distribution and the quantity of solar radiation influence plant growth, development and productivity, assuming that other environmental parameters are not limiting. While the energetics of solar radiation use (photosynthesis), the effect of the timing of solar radiation exposure (photoperiod), and the response to the direction of solar radiation (phototropism) have been and continue to be studied, less is known about the role of the photomorphogenetic solar radiation spectral composition in growing plants. Changes in red radiation (R, 600-700 $\mathrm{nm}$ ), in far-red radiation (FR, 720-740 nm) or in blue radiation $(\mathrm{B}, 400-500 \mathrm{~nm})$ in the growing environ-

Paper received 27.10.2009; accepted 16.02.2010

Ing. Evelia Schettini, Ing. Giuliano Vox: Department of Engineering and Management of the Agricultural, Livestock and Forest Systems Department (PROGESA), University of Bari, via Amendola 165/A 70126 Bari (Italy). E-mail: evelia.schettini@agr.uniba.it.

The experimental tests, the data processing and the editorial work were shared equivalently among the Authors. ment affect plant photomorphogenesis involving the activation of photoreceptors, such as the phytochrome and the cryptochrome. It has become common practice to characterise the phytochrome response in terms of the bichromatic R/FR ratio of the photon fluence rate in the red to that in the far-red [Baraldi 1994; Kittas 1998; Kittas 1999; Magnani 2004 and 2007; Murakami 1996; Oren-Shamir 2001; Smith 1982; Takaichi 2000; Wilson 2001]. Relatively little literature is available on the function of the blue-radiation receptors named cryptochromes [Kittas 1999; Moe 2002].

The aim of this paper is to investigate the influence of innovative photoselective and photoluminescent greenhouse plastic films, made to modify the spectral distribution of the transmitted solar radiation, on the growth of cherry and peach trees.

\section{Materials and methods}

Innovative transparent plastic films were used as covering materials for horticultural greenhouses at the experimental farm of the University of Bari in Valenzano (Bari, Italy), at latitude $41^{\circ} 05^{\prime} \mathrm{N}$, from April 2007 to September 2007. Five innovative experimental films, with a thickness of $200 \mu \mathrm{m}$, were manufactured in co-operation with two industrial companies: the experimental additives were supplied by VIBA Company (Tradate, Varese, Italy) and the film extrusion was carried out by Si.Sac. Company (Ragusa, Italy). Two photoselective films, named GREEN4\% and GREEN2\%, were made by adding $4 \%$ and $2 \%$ green transparent Vibatan polyethylene, respectively, as well as anti-ultraviolet (UV) stabilisers. Three photoluminescent films, named RED, BLUE and REDBLUE, were created by adding masterbatches that have the capacity to absorb UV radiation in order to retransmit it in the wavelength band of the red, blue and red-blue radiation, respectively; further anti-UV stabilisers were not added to these films. A low-density polyethylene film (LDPE) manufactured by Si.Sac Company with anti-UV stabilisers and a thickness of $200 \mu \mathrm{m}$ was chosen as the control. The films were in- 
stalled on six steel arched roof greenhouses $(6.00 \mathrm{~m} \mathrm{x}$ $6.00 \mathrm{~m}$, ridge height of $3.80 \mathrm{~m}$, gutter height of 2.40 $\mathrm{m})$, East-West oriented, each with two ample vents to provide adequate ventilation.

One year cherry trees (cultivar Lapins on Gisela 6 rootstock) and one year peach trees (cultivar Messapia on Missour rootstock) were grown in pots with a diameter of $0.45 \mathrm{~m}$. The pots were located inside the greenhouses and in open field conditions; 6 trees of each species were used for each treatment. Before starting the trial, the trees were pruned: the main branch for each peach tree was chosen while the lateral branches close to the main branch and some buds were eliminated; the cherry trees were cut at a height of $1.20 \mathrm{~m}$, then only the first 2 buds were left on the apical shoot while the following 8-10 buds were manually eliminated.

During the field test, tree growth parameters, such as cherry apical shoots and peach shoots, were collected periodically in open field conditions and inside the greenhouses covered with the different films.

In order to evaluate the modifications of the films on the R/FR ratio of the natural radiation, an apparatus with a thin metal frame and a portable GER 2600 spectroradiometer was used in the experimental field. The measurements of the spectral irradiance in the wavelength range from 300 to $2500 \mathrm{~nm}$ were carried out using a reflective surface with a white reflectance coating of barium sulphate, characterised by a certified reflectivity equal to 99\% (Labsphere, New Hampshire, USA). The tests inside and outside the greenhouses were performed at noon on 20 June 2007 in clear sky conditions. The R/FR ratio of the photon fluence rate in the red to that in the far-red was calculated adopting the narrow bandwidth for the determination of the red $(650-670 \mathrm{~nm})$ and the far-red $(720-$ $740 \mathrm{~nm}$ ) radiation by:

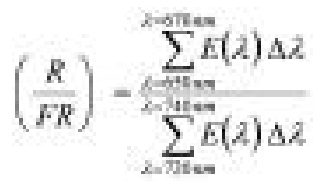

where $\mathrm{E}(\lambda), \mu \mathrm{mol} \mathrm{m} \mathrm{m}^{-2} \mathrm{~s}^{-1} \mathrm{~nm}^{-1}$, is the spectral irradiance at wavelength $\lambda, \mathrm{nm} ; \Delta \lambda$ is the wavelength interval equal to $1.5 \mathrm{~nm}$.

The transmissivity of the films was measured at the "Laboratory for the Measurement of the Radiometric Properties of Materials" of the PROGESA Department. Spectral direct transmissivity of the films in the solar range was measured by a double beam UV-VISNIR spectrophotometer (Lambda 950, Perkin Elmer Instruments, Norwalk, CT, USA). Measurements were carried out in the wavelength band from 200 to $2500 \mathrm{~nm}$ in steps of $10 \mathrm{~nm}$ using radiation with a direct perpendicular incidence. Spectral total transmissivity was measured by means of an integrating sphere (diameter $60 \mathrm{~mm}$ ) used as the receiver of the Lambda 950 spectrophotometer, with a double beam comparative method [Wendlandt 1966]. Spectral diffuse transmissivity was calculated by subtracting the direct transmissivity from the total transmissivity. The transmissivity coefficients were calculated as weighted average values of the transmissivity over the wavelength interval $300-2500 \mathrm{~nm}$ for the solar range, and 400-700 nm for the PAR range, using the spectral distribution of the terrestrial solar radiation as the weighting function [Papadakis 2000].

The transmissivity in the long wave infra-red radiation (LWIR) range between $2500 \mathrm{~nm}$ and $25000 \mathrm{~nm}$ was measured by a FT-IR spectrophotometer (1760 X, Perkin Elmer Instruments, Norwalk, CT, USA). The LWIR transmissivity coefficient was calculated as the average value over the wavelength interval $7500 \mathrm{~nm}$ $12500 \mathrm{~nm}$, at which bodies at ambient temperature have the maximum energy emission as expressed by Planck's spectral distribution of emissive power [Papadakis 2000; Siegel 1972].

\section{Results and discussion}

Radiation quality parameters under the covering films and outside, which were obtained from field measurements during a sunny, summer day at the experimental farm, are shown in Table 1. The LDPE film and the photoluminescent covering films did not induce significant variations in the R/FR ratio as compared to the $(\mathrm{R} / \mathrm{FR})_{\mathrm{ext}}$ value, obtained in absence of the films. Differently, both the photoselective films showed lower values of the R/FR ratio in comparison to the value obtained in absence of the films: the (R/FR) ratio was equal to 1.01 under the greenhouse covered with the GREEN2\% film and equal to 0.93 under the GREEN4\% film, while the (R/FR) $)_{\text {ext }}$ ratio, obtained in absence of the films, was equal to 1.15 .

The radiometric coefficients calculated in the solar, in the PAR, in the UV and in the LWIR wavelength ranges of the covering films used in the cultivation test are shown in Table 2 . The transmissivity coefficient in the PAR range, which expresses the quantity of solar PAR radiation transmitted by the covering material, strongly influences crop growth and yield. The photoluminescent films and the LDPE film were characterised by similar total transmissivity coefficients in the PAR range: this coefficient was equal to

\begin{tabular}{|c|c|c|}
\hline & $(\mathrm{R} / \mathrm{FR})_{\mathrm{ext}}$ & $(\mathrm{R} / \mathrm{FR})$ \\
\hline LDPE & 1.14 & 1.13 \\
\hline RED & 1.14 & 1.13 \\
\hline BLUE & 1.14 & 1.13 \\
\hline RED-BLUE & 1.14 & 1.13 \\
\hline GREEN2\% & 1.15 & 1.01 \\
\hline GREEN4\% & 1.15 & 0.93 \\
\hline
\end{tabular}

TABLE $1-(\mathrm{R} / \mathrm{FR})$ ratio under the films and outside (subscript ext), evaluated on 20 June 2007 at noon during a sunny day, at the experimental farm of the University of Bari in Valenzano (Bari, Italy) 
$83.4 \%$ for the RED and RED-BLUE films, equal to $83.8 \%$ for the BLUE film, and equal to $84.1 \%$ for the LDPE film. The PAR total transmissivity coefficient was equal to $73.8 \%$ and to $67.4 \%$ for the GREEN2\% and GREEN4\% photoselective film, respectively.

In the LWIR range the transmissivity coefficient ranged from $51.4 \%$ (GREEN2\%) to $60.2 \%$ (REDBLUE).

The fluorescent effect of the RED, BLUE and RED-BLUE photoluminescent films was not measurable by means of the spectrophotometer; this effect was not detected also by the spectroradiometer measurements due to the low value of the radiation energy moved from the UV spectrum to the red, blue and red-blue spectrum, respectively.

The spectral transmissivity of the photoselective films, of the photoluminescent films and of the LDPE film in the solar range is shown in figure 1 . The photoselective films had a significant peak of transmissivity around $550 \mathrm{~nm}$ and had low values of transmissivity at wavelengths higher than $600 \mathrm{~nm}$, including the wavelength band which can be associated with the red colour, from $600 \mathrm{~nm}$ to $700 \mathrm{~nm}$. Both the photoselective films had high transmissivity at wavelengths higher than $800 \mathrm{~nm}$ in the infra-red region where solar radiation has no direct influence on plant growth but contributes to increase the thermal level of the protected area. The LDPE film showed a rather uniform spectral distribution of the transmissivity in the PAR and in the infra-red region.

The radiometric properties of the covering films also affected temperature and relative humidity inside the

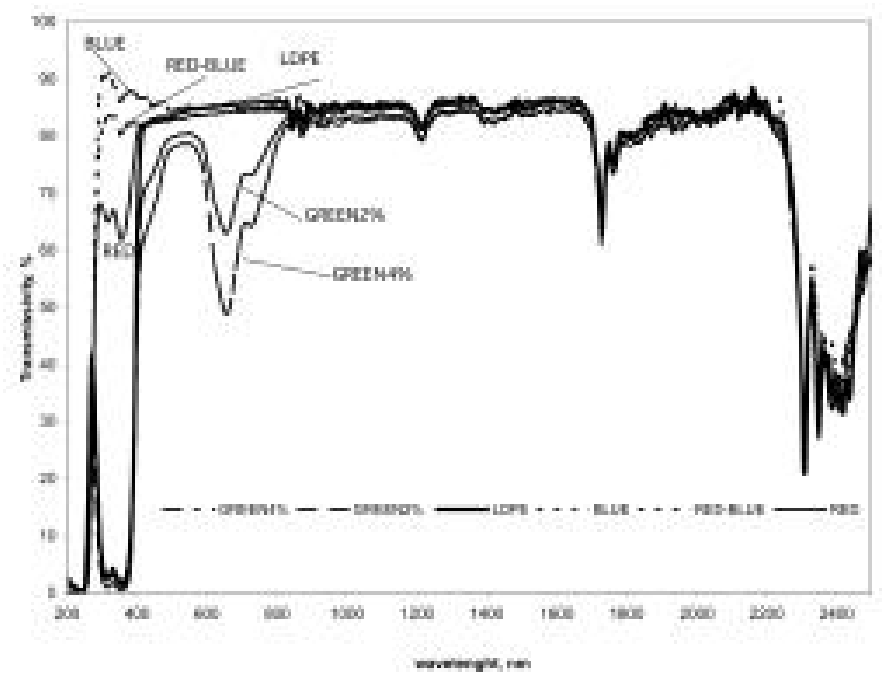

Fig. 1 - Total spectral transmissivity of the photoselective films, GREEN4\% and GREEN2\%, of the fotoluminescent films, RED, BLUE and RED-BLUE, and of the LDPE film, in the wavelength range $200-2500 \mathrm{~nm}$.

greenhouses. The average values of the maximum, minimum and mean daily greenhouse air temperature and relative humidity are shown in Table 3, calculated over the cultivation period. Temperature and relative humidity of the external air are presented for comparison. Inside the greenhouses the films induced maximum air temperatures that ranged from $34.5{ }^{\circ} \mathrm{C}$ (GREEN4\%) to $36.6{ }^{\circ} \mathrm{C}$ (RED-BLUE) while slight differences were recorded for the mean air temperatures, ranging from $24.1{ }^{\circ} \mathrm{C}$ (GREEN4\%) to $24.9{ }^{\circ} \mathrm{C}$ (RED-

\begin{tabular}{|c|c|c|c|c|c|}
\hline & Solar total (\%) & $\begin{array}{c}\text { PAR total } \\
(\%)\end{array}$ & PAR diffuse (\%) & $\begin{array}{c}\text { UV total } \\
(\%)\end{array}$ & $\begin{array}{c}\text { LWIR } \\
(\%)\end{array}$ \\
\hline LDPE & 82.7 & 84.1 & 40.6 & 3.8 & 53.7 \\
\hline RED & 83.5 & 83.4 & 24.5 & 65.7 & 59.9 \\
\hline BLUE & 84.3 & 83.8 & 17.0 & 82.5 & 58.6 \\
\hline RED-BLUE & 83.9 & 83.4 & 24.5 & 82.0 & 60.2 \\
\hline GREEN2\% & 76.0 & 73.8 & 34.5 & 1.9 & 51.4 \\
\hline GREEN4\% & 72.1 & 67.4 & 30.3 & 4.6 & 54.7 \\
\hline
\end{tabular}

TABLE 2 - Transmissivity coefficients of the greenhouse films; PAR, photosynthetically active radiation; UV, ultra violet radiation; LWIR, long wave infra-red radiation.

\begin{tabular}{|c|c|c|c|c|c|c|}
\hline & \multicolumn{3}{|c|}{ Air temperature $\left({ }^{\circ} \mathrm{C}\right)$} & \multicolumn{3}{c|}{ Relative Humidity (\%) } \\
\hline & Max & Mean & Min & Max & Mean & Min \\
\hline GREEN4\% & 34.5 & 24.1 & 16.2 & 78.9 & 52.8 & 26.2 \\
\hline GREEN2\% & 36.2 & 24.7 & 16.3 & 79.4 & 51.8 & 23.3 \\
\hline RED-BLUE & 36.6 & 24.9 & 16.5 & 78.0 & 50.7 & 22.3 \\
\hline BLUE & 36.3 & 24.7 & 16.1 & 79.3 & 51.8 & 23.5 \\
\hline RED & 36.5 & 24.7 & 16.3 & 78.7 & 51.2 & 22.3 \\
\hline LDPE & 35.6 & 24.5 & 16.4 & 78.0 & 51.2 & 23.0 \\
\hline Open field & 30.7 & 23.7 & 17.5 & 73.3 & 53.3 & 32.1 \\
\hline
\end{tabular}

TABLE 3 - Average values of the mean, maximum and minimum daily air temperature and relative humidity inside the greenhouses and in open field conditions; max, maximum; min, minimum. 


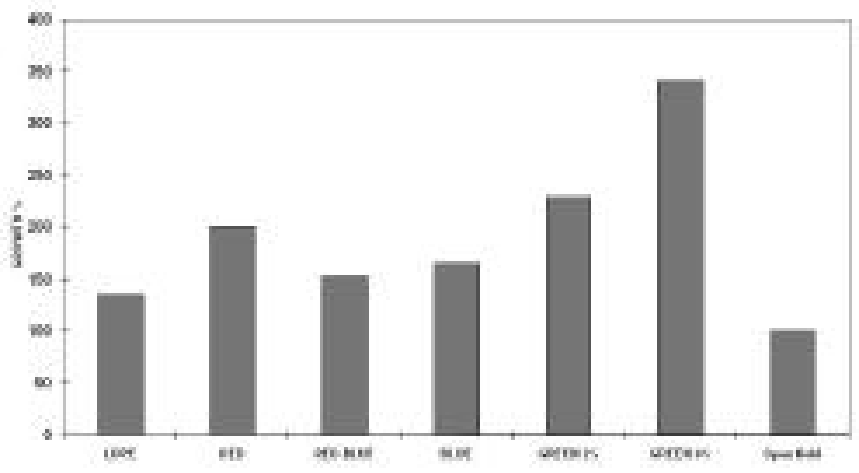

Fig. 2 - Relative peach annual shoot growth expressed as a percentage of the shoots length (open field as control=100\%).

BLUE). The minimum night air temperatures under the greenhouses covered with the films, which ranged from $16.1{ }^{\circ} \mathrm{C}$ (BLUE) to $16.5{ }^{\circ} \mathrm{C}$ (RED-BLUE), were lower than the external air temperature $\left(17.5^{\circ} \mathrm{C}\right)$; this was due to the high value of the LWIR transmissivity coefficients of the films (Tab. 2) [Vox 2007].

During the field test, the influence of the different plastic films on the vegetative activity of the cherry and peach trees was studied. The related annual growth, expressed as a percentage of shoots length increase, in comparison with the open field (increase set to $100 \%$ ), is reported in Figures 2 and 3 for the cherry

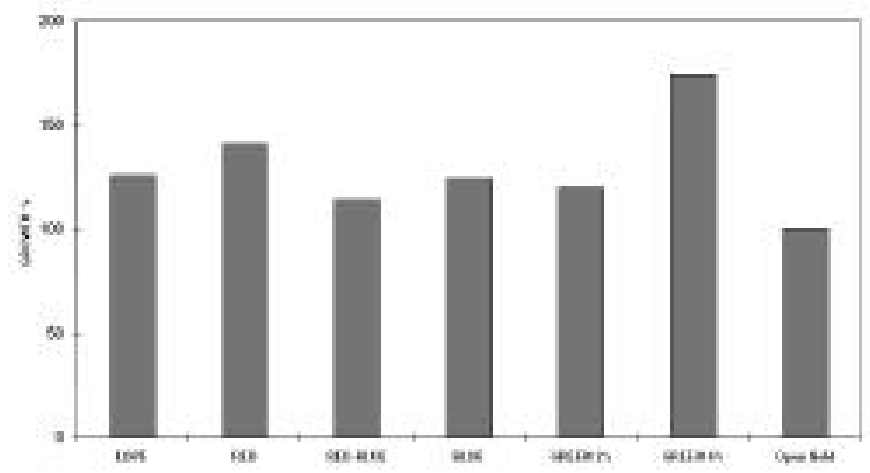

Fig. 3 - Relative cherry annual apical shoot growth expressed as a percentage of the shoots length (open field as control=100\%).

and peach trees, respectively. A high increase of the vegetative activities was observed for the trees located inside the greenhouses covered with the photoselective films and with the photoluminescent films in comparison to the trees grown under the LDPE film and in open field conditions. However, different responses to vegetative activities were observed under the films, depending on the species, with a higher shoots growth rate in the peach trees compared to the cherry trees. The photoselective GREEN4\% film significantly enhanced the growth of the cherry and peach trees in comparison to the trees cultivated under
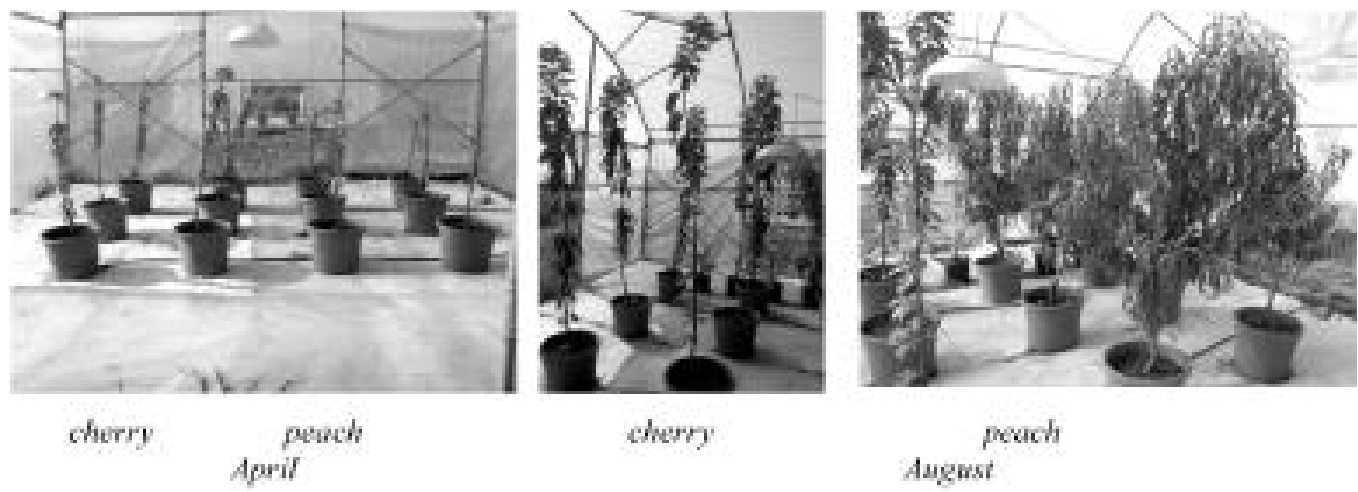

Fig. 4 - Peach and cherry trees cultivated under the photoselective GREEN4\% film in April 2007 (at the beginning of the test) and in August 2007.

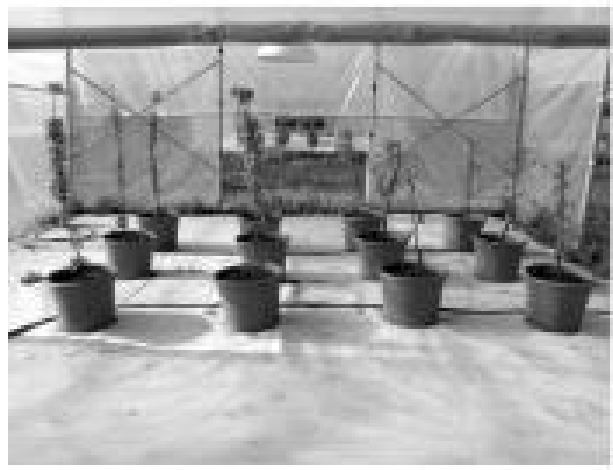

cherry

$$
\text { April }^{\text {peach }}
$$

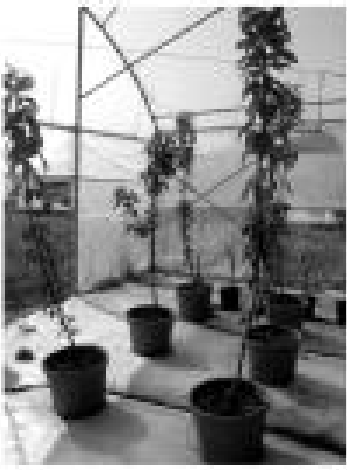

chern

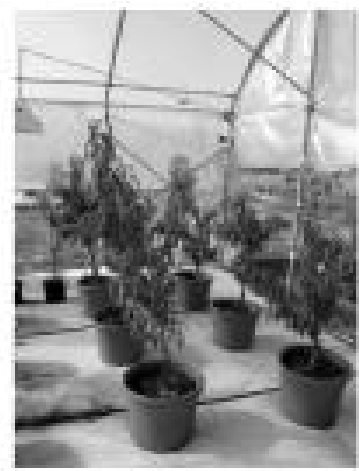

peach

Fig. 5 - Peach and cherry trees cultivated under the LDPE film in April 2007 (at the beginning of the test) and in August 2007. 
the other greenhouse films (Fig. 4). According to literature [Clifford 2004] the decrease of the R/FR ratio of the photoselective GREEN4\% film caused cherry trees and peach trees to respond by increasing extension growth. The lowest growth rate for cherry and peach trees was calculated for the trees grown in open field conditions and under the LDPE film (Fig. 5).

The RED film also induced significant shoot length increases in the peach trees, while the plants grown under the BLUE film recorded lower values of the annual increase of the shoots (Fig. 2). The different growth under the RED and BLUE covering films cannot be attributed to differences in temperatures, which were very similar (Tab. 3), but only in the presence of the red and blue radiation, respectively.

\section{Conclusion}

The experimental field test showed that it is possible to alter the quality of the solar radiation under covering plastic films, thus influencing the photomorphogenesis of trees for potential economic benefit or to facilitate cultivation. The manipulation of the solar radiation spectrum and thus of the vegetative and reproductive activity of the trees, can have different purposes including controlling the tree size. The results showed that the modifications of the solar spectral distribution mainly in the R and FR wavelength band affected the vegetative activity of the trees influencing the shooting growth of the peach and cherry trees.

It is necessary to continue research on photomorphogenesis both to elucidate the physiological mechanisms through which plants control their growth and to design new films with specific radiometric properties that can meet the diverse needs of various sectors involved in tree protected cultivation. Such films can be used in place of chemical growth regulators, thereby increasing the sustainability of the agricultural production.

\section{Acknowledgements}

The present work was carried out under the Project "Research for the improvements of the fruit trees protected cultivation in Southern Italy - FRU.MED.; subproject DAFME", funded by the Italian Ministry of Agriculture and Forestry Policy; publication $\mathrm{n}^{\circ} 76$.

The authors thank VIBA S.p.A. (Tradate, VA, Italy) for the cooperation in the development of the experimental films.

The authors thank geom. Michele Cosmo of the University of Bari for the spectrophotometric measurements and Dr. Luigi Lo Russo and Mr. Francesco Ferrulli of the University of Bari for their cooperation in the field tests.

\section{References}

Baraldi R., Rossi F., Facini O., Fasolo F., Rotondi A., Magli M., Nerozzi F. Light environment, growth and morphogenesis in a peach tree canopy. Physiologia Plantarum, 1994, 91, 339-345.

Clifford S.C., Runkle E.S., Langton F.A., Mead A., Foster S.A., Pearson S., Heins R.D. Height control of poinsettia using photoselective filters. HortScience, 2004, 39 (2), 383-387.

Dichio B., Xiloyannis C., Nuzzo V., Montanaro G., Palese A.M. Posharvest regulated deficit irrigation of peach tree in a mediterranean enviroment: effects on vegetative growth and yield. Acta Horticulture, 2004, 664, 169174.

Kittas C., Baille A. Determination of the spectral properties of several greenhouse cover materials and evaluation of specific parameters related to plant response. Journal of Agricultural Engineering Research, 1998, 71, 193-202.

Kittas C., Baille A., Giaglaras P. Influence of covering material and shading on the spectral distribution of light in greenhouses. Journal of Agricultural Engineering Research, 1999, 73, 341-351.

Magnani G., Bonora M., Destro M., Filippi F. Nuovi film luminescenti di copertura: primi risultati su colture ortofloricole. Colture Protette 2004, 33 (2), 89-95.

Magnani G., Bonora M., Destro M., Filippi F. Effetti del film luminescente rosso sulla produzione di garofano. Colture Protette 2007, 36 (4), 72-80.

Moe R., Morgan L., Grindal G. Growth and plant morphology of cucumis savitus and Fuchsia x hybrid are influenced by light quality during the photoperiod and by diurnal temperature alternations. Acta Horticulturae, 2002, 580, 229-234.

Murakami K., Cui H., Kiyota M., Takemura Y., Oi R., Aiga, I. Covering materials to control plant growth by modifying the spectral balance of daylight. Plasticulture, 1996 , 110 (2), 2-14.

Oren-Shamir M., Gussakovsky E.E., Shpiegel E., NissimLevi A., Ratner K., Ovadia R., Giller Y.E., Shahak Y. Coloured shade nets can improve the yield and quality of green decorative branches of Pittosporum variegatum. Journal of Horticultural Science \& Biotechnology, 2001, 76 (3), 353-361.

Papadakis G., Briassoulis D., Scarascia Mugnozza G., Vox G., Feuilloley P., Stoffers J.A. Radiometric and Thermal Properties of, and Testing Methods for, Greenhouse Covering Materials. Journal of Agricultural Engineering Research, 2000, 77 (1), 7-38.

Rajapakse N.C., Young R.E., McMahon M.J., Oi R. Plant height control by photoselective filters: current status and future prospects. HortTechnology, 1999, 9 (4), 618624.

Shahak Y., Gussakovsky E.E., Cohen Y., Lurie S., Stern R., Kfir S., Naor A., Atzmon I., Doron I., Greenblat-Avron Y. ColorNets: a new approach for light manipulation in fruit trees. Acta Horticulturae, 2004, 636, 609-616.

Siegel R., Howell J.R. Thermal Radiation Heat Transfer. McGraw-Hill, 1972, New York.

Smith, H. Light quality, photoperception, and plant strategy. Ann. Reviews of Plant Physiology, 1982, 33: 481-518.

Takaichi M., Shimaji H., Higashide T. Effect of red/far-red photon flux ratio of solar radiation on growth of fruit veg- 
etable seedlings. Acta Horticulturae 2000, 514, 147-156.

Vox G., Schettini E. Evaluation of the radiometric properties of starch-based biodegradable films for crop protection. Polymer Testing, 2007, 26 (5), 639-651.

Wendlandt W.W., Hecht H.G.. Reflectance spectroscopy, John Wiley and Sons, New York, 1966, 253-274.

Wilson S. B., Rajapakse N. C. Use of photoselective plastic films to control growth of three perennial salvias. Journal of Applied Horticulture, 2001, 3 (2), 71-74.

\section{SUMMARY}

The aim of this paper was to investigate the radiometric properties of innovative covering films for protected cultivation capable of modifying the spectral distribution of the transmitted radiation and thus the vegetative activity. Two photoselective films, three photoluminescent films and one low-density polyethylene film were used as greenhouse coverings for cherry trees and peach trees, grown in pots. The photoselective films were characterised by a reduction of the R/FR ratio in comparison to the natural solar radiation. Tree growth parameters, such as the apical shoot of cherry trees and the shoot of peach trees, were monitored. Different responses to vegetative activities were observed under the films, depending on the species, with a higher shoots growth rate in the peach with respect to the cherry. The photoselective film characterised by the lowest R/FR ratio significantly enhanced the growth of cherry and peach trees in comparison to the trees cultivated under the other greenhouse films.

Keywords: solar radiation, R/FR ratio, photomorphogenesis. 